\title{
COMMUTATORS OF RIESZ TRANSFORMS WITH LIPSCHITZ FUNCTIONS RELATED TO MAGNETIC SCHRÖDINGER OPERATORS
}

\author{
DONGYONG YANG
}

Abstract. Let $A:=-(\nabla-i \vec{a}) \cdot(\nabla-i \vec{a})+V$ be a magnetic Schrödinger operator on $L^{2}\left(\mathbb{R}^{n}\right)$, $n \geqslant 2$, where $\vec{a}:=\left(a_{1}, \cdots, a_{n}\right) \in L_{\mathrm{loc}}^{2}\left(\mathbb{R}^{n}, \mathbb{R}^{n}\right)$ and $0 \leqslant V \in L_{\mathrm{loc}}^{1}\left(\mathbb{R}^{n}\right)$. In this paper, the author shows that the commutators of the Riesz transforms $L_{k} A^{-1 / 2}, k \in\{1, \cdots, n\}$, with functions in Lipschitz space $\operatorname{Lip}_{\alpha}\left(\mathbb{R}^{n}\right)$ for $\alpha \in(0,1)$, are bounded from $L^{p}\left(\mathbb{R}^{n}\right)$ to $L^{q}\left(\mathbb{R}^{n}\right)$, where $1 / p-$ $1 / q=\alpha / n$ and $L_{k}$ is the closure of $\frac{\partial}{\partial x_{k}}-i a_{k}$ in $L^{2}\left(\mathbb{R}^{n}\right)$. Let $\rho$ be an admissible function modeled on the known auxiliary function determined by the Schrödinger operator $-\triangle+V$. The author also characterizes a localized Lipschitz space $\operatorname{Lip}_{\alpha, \rho}\left(\mathbb{R}^{n}\right)$ in terms of the localized Riesz transforms $\left\{\widetilde{R}_{j}\right\}_{j=1}^{n}$ and their adjoint operators.

Mathematics subject classification (2010): 42B20, 42B35.

Keywords and phrases: Riesz transform, magnetic Schrödinger operator, commutator, Lipschitz space, admissible function.

\section{REFERENCES}

[1] S. Chanillo, A note on commutators, Indiana Univ. Math. J. 31 (1982), 7-16.

[2] R. R. COIFMAN, R. RochBERG AND G. WeIss, Factorization theorems for Hardy spaces in several variables, Ann. of Math. (2) 103 (1976), 611-635.

[3] X. T. Duong And E. M. OuhabaZ And L. Yan, Endpoint estimates for Riesz transforms of magnetic Schrödinger operators, Ark. Mat. 44 (2006), 261-275.

[4] X. T. Duong And L. Yan, Commutators of Riesz transforms of magnetic Schrödinger operators, Manuscripta Math. 127 (2008), 219-234.

[5] J. DZiubanís Ki, G. Garrigós, T. Martínez, J. L. Torrea And J. Zienkiewicz, BMO spaces related to Schrödinger operators with potentials satisfying a reverse Hölder inequality, Math. Z. 249 (2005), 329-356.

[6] L. Grafakos, Classical And Modern Fourier Analysis, Pearson Education, Inc., Upper Saddle River, N. J., 2004.

[7] Z. Guo, P. Li And L. PEng, $L^{p}$ boundedness of commutators of Riesz transforms associated to Schrödinger operator, J. Math. Anal. Appl. 341 (2008), 421-432.

[8] S. JANSON, Mean oscillation and commutators of singular integral operators, Ark Mat. 16 (1978), 263-270.

[9] Y. Liu And J. Sheng, Some estimates for commutators of Riesz transforms associated with Schrödinger operators, J. Math. Anal. Appl. 419 (2014), 298-328.

[10] J. M. MARTELL, Sharp maximal functions associated with approximations of the identity in spaces of homogeneous type and applications, Studia Math. 161 (2004), 113-145.

[11] E. M. OuhabaZ, Analysis of Heat Equations on Domains, Princeton University Press, Princeton, N. J., 2004.

[12] Z. SHEN, $L^{p}$ estimates for Schrödinger operators with certain potentials, Ann. Inst. Fourier (Grenoble) 45 (1995), 513-546.

[13] Da. YAng AND Do. YAng, Characterizations of localized $\mathrm{BMO}\left(\mathbb{R}^{\mathrm{n}}\right)$ via commutators of localized Riesz transforms and fractional integrals associated to Schrödinger operators, Collect. Math. 61 (2010), 65-79. 
[14] Da. YAng, Do. YAng AND Y. Zhou, Endpoint properties of localized Riesz transforms and fractional integrals associated to Schrödinger operators, Potential Anal. 30 (2009), 271-300.

[15] DA. YANG, Do. YANg AND Y. Zhou, Localized Morrey-Campanato spaces on metric measure spaces and applications to Schrödinger operators, Nagoya Math. J. 198 (2010), 77-119.

[16] D. YANG AND Y. ZHou, Localized Hardy spaces $H^{1}$ related to admissible functions on RD-spaces and applications to Schrödinger operators, Trans. Amer. Math. Soc. 363 (2011), 1197-1239. 